\title{
FURTHER ANALYSIS OF THE INTERNATIONAL INTERCOMPARISON STUDY (ICS)
}

\author{
E. M. SCOTT', G. T. COOK ${ }^{2}$, D. D. HARKNESS ${ }^{3}$, B. F. MILLER ${ }^{3}$ and M. S. BAXTER ${ }^{4}$
}

ABSTRACT. The major findings of the Intercomparison Study (ICS) have already been published (Scott, Long \& Kra 1990), but a number of questions remain unresolved. We address here some issues of user and technical relevance, which include: 1) further investigation of the quoted errors and their relation to the perceived precision and accuracy, which is of interest to users of ${ }^{14} \mathrm{C}$ dates; 2 ) the analysis of the known-age wood samples provided in Stages 2 and 3 of the ICS; 3) an investigation of the corresponding $\delta^{13} \mathrm{C}$ data base, of more technical relevance to laboratories.

\section{INTRODUCTION}

The original analysis of the data generated during the Intercomparison Study (ICS) was intended to address a number of key topics, in particular: 1) the role of the quoted error as a measure of internal consistency as indicated by the duplicate analyses; 2) the existence, or otherwise, of systematic biases and the role of the quoted error in adequately explaining any such interlaboratory variation; 3 ) a comparison of the performance of each laboratory type: liquid scintillation counting (LSC), gas proportional counting (GPC) and accelerator mass spectrometry (AMS).

To answer these questions, we evaluated three measures of laboratory performance, one that assessed systematic bias and two (error multipliers) that attempted to quantify the inter- and intralaboratory variation in a simple manner (Scott et al. 1990). The available data permit further investigation that may be useful to users of ${ }^{14} \mathrm{C}$ data.

First, we consider further the question of error, and describe some new evaluations, now completed, to explore more thoroughly the relationship of quoted error, error multiplier and absolute error. We also examine the results by grouping of quoted error.

Second, although ICS had three stages, only the 2 nd and 3rd stages involved natural samples Stage 2 provided homogenized, pretreated samples of cellulose and humic acid, both of which could be directly related to whole samples of wood and peat provided in Stage 3. In addition, the cellulose and wood in Stages 2 and 3 were provided by the Belfast Palaeoecology Laboratory and had been tree-ring dated. In the previous analysis, little use was made of the tree-ring dates; here we consider the spread of ${ }^{14} \mathrm{C}$ measurements in these samples and its relation to the "true" age.

Finally, we consider some of the additional information provided by laboratories, and their relation to the results, in particular, $\delta^{13} \mathrm{C}$.

\section{Further Investigation of the Level of Variability}

In this section, we concentrate on results from Stage 3 and on the Internal Error Multiplier (IEM). This is calculated from the differences between the duplicate samples, and quantifies the reproducibility of results. (Appendix 1 defines the model and estimation of the IEM). In this sense, the IEM is an analog to the Level-3 error, which is "based on the statistical analysis of count rates of samples repeatedly reprocessed through the entire procedure in the lab" (Long \& Kalin 1990: 330).

\footnotetext{
${ }^{1}$ Department of Statistics, University of Glasgow, Glasgow G12 8QW Scotland ${ }^{2}$ Radiocarbon Laboratory, SURRC, East Kilbride, Glasgow G75 OQU Scotland ${ }^{3} \mathrm{NERC}{ }^{14} \mathrm{C}$ Laboratory, SURRC, East Kilbride, Glasgow G75 OQU Scotland ${ }^{4}$ IAEA International Marine Laboratory, MC 98000 Monaco
} 
EM against m.q.e.

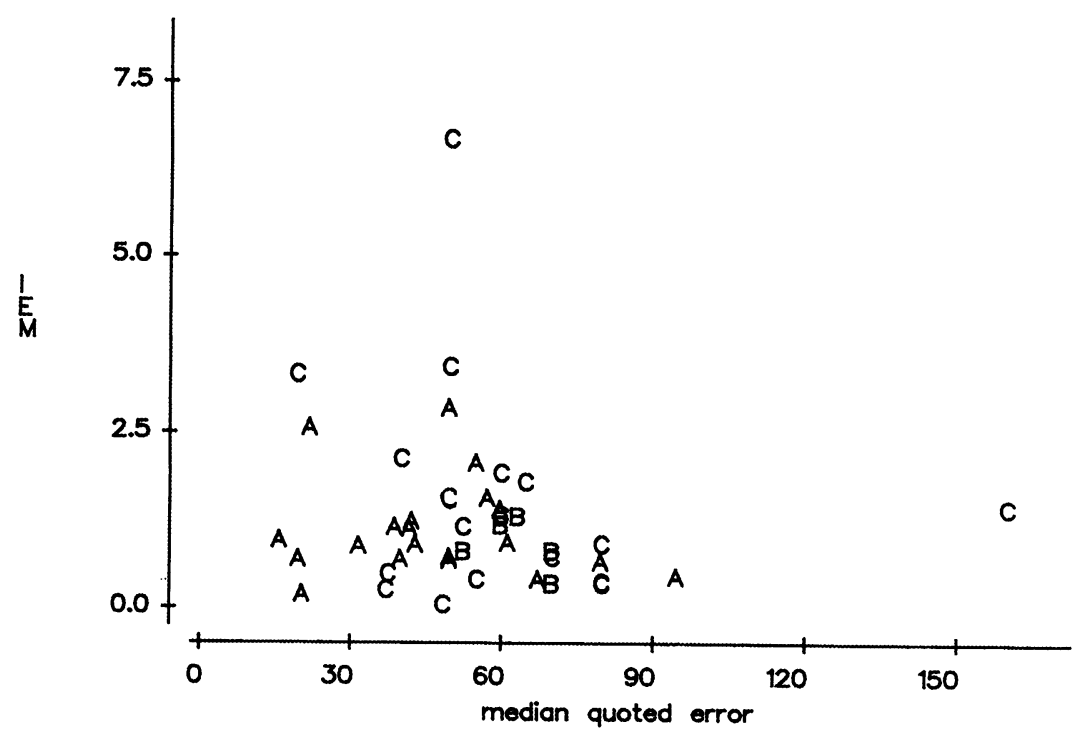

Fig. 1. Internal error multiplier plotted against median quoted error. Points are labeled as follows: A - GPC; B - AMS; C - LSC.

A total of 44 labs submitted results for Stage 3. Figure 1 shows the individual laboratory IEM plotted against the median quoted error (mqe). The correlation co-efficient, estimated as -0.130 , is not statistically significant, so there is no evidence of a relation between mqe and IEM. We find no evidence of differing performances in IEM among the three lab types, nor do we find any significant difference in IEM if we group laboratories according to their mqe. For this work, we have chosen the following categorization to ensure adequate numbers of laboratories in each group:

$$
\begin{aligned}
& \text { mqe } \leq 30 \\
& 30 \leq \text { mqe } \leq 50 \\
& 50<\text { mqe } \leq 70 \\
& \text { mqe }>70 .
\end{aligned}
$$

Tables $1 \mathrm{~A}$ and $\mathrm{B}$ summarize the IEM calculations.

TABLE 1A. Summary of the Distribution of IEM in Stage 3, by Lab Type

\begin{tabular}{lccc}
\hline & & Lab tvpe & \\
\cline { 3 - 4 } & GPC & AMS & LSC \\
\hline Average IEM & 1.08 & 0.9 & 1.55 \\
No. of labs & 20 & 6 & 18 \\
\hline
\end{tabular}

TABLE 1B. Summary of the Distribution of IEM in Stage 3, by mqe

\begin{tabular}{lcccc}
\hline & \multicolumn{4}{c}{ Median quoted error (mqe) } \\
\cline { 3 - 5 } Average IEM & mqe $\leq 30$ & $30<$ mqe $\leq 50$ & $50<$ mqe $\leq 70$ & mqe $>70$ \\
& 1.52 & 1.53 & 1.10 & 0.66 \\
\hline
\end{tabular}


TABLE 1C. Index of Homogeneity on Duplicate Samples

\begin{tabular}{clc}
\hline & Sample & \\
\cline { 2 - 3 } Wood A & Shell & Peat \\
\hline 1.65 & 2.04 & \\
$1.64^{*}$ & $1.07^{*}$ & 1.37 \\
\hline
\end{tabular}

*After removal of a single outlier

In general, we conclude that the quoted error for most laboratories adequately described the reproducibility of their results. However, this is not the only component of variability of interest, since we must also assess the comparability of results, and hence, the component due to different laboratories dating the same material. One measure of comparability that can be simply quantified is that of an index of homogeneity $\sigma_{\mathrm{w}}$ (Ward \& Wilson 1978; Wilson \& Ward 1981) (see Appendix). The index was originally defined to compare simultaneity and combine a group of ${ }^{14} \mathrm{C}$ dates typically from the same laboratory. We apply this technique to groups of dates of the same material, but from different laboratories. The index defines an overall level of variation, and is based on a model that assumes, on average, laboratories are measuring the same ${ }^{14} \mathrm{C}$ activity, but also permits the variability around the true mean level for lab $i$, to be modeled as $\sigma_{\mathrm{W}}^{2} s_{i}^{2}$, where $s_{i}$ represents the quoted error. Thus, the index is a sample rather than laboratory-specific measure, and includes a component of variation due to the natural variability within the sample material. The IEM, based on duplicates, provides the laboratory equivalent of the index.

Initially, the index had been calculated on the duplicate differences for the wood, shell and peat samples. Table $1 \mathrm{C}$ shows the results. Since the index generally exceeds 1 , we see some evidence of overdispersion in the results.

The index was then calculated for all the samples in Stage 3, with duplicate results no longer combined. Table $2 \mathrm{~A}$ shows the index and the estimate of the 'true' ${ }^{14} \mathrm{C}$ age. Again, we see evidence of overdispersion. All the wood samples have an index of $c a .2$, the peat sample gives the lowest value at 1.80 and the shell sample, the highest, at 3.04. This ordering is further supported by the known provenience of each sample. The peat samples were milled before dispatch, the wood samples consisted of either 20 -year or 30-year sections; the shells were generally whole, and of the same species taken from a large deposit (Cook et al. 1990), but were believed to have come from a well-defined archaeological context. This analysis was repeated for two subclassifications of the data - by lab type and by median quoted error. Table $2 \mathrm{~B}$ shows that GPC and LSC labs generally measure the same ${ }^{14} \mathrm{C}$ activity, but that the index for LSC labs tends to be higher than those for GPC labs. AMS lab results have noticeably lower indices, indicative of 1) a more consistent set of results, and 2) more appropriate quoted errors. Interestingly, we see some differences in the average ${ }^{14} \mathrm{C}$ activity among the different lab types, this being most pronounced in the two younger wood samples (B and $C$ ).

Table $2 \mathrm{C}$ shows the indices calculated for the different subgroups of labs, classified according to mqe. No overall pattern emerges from this table, other than evidence of overdispersion in the results. The analytical approach described here assumes that the overdispersion can be modeled as additional random variation. Previously, we estimated systematic components of intralaboratory variation, namely bias. The latter analysis also showed evidence of significant differences among laboratories. More recently, the IAEA 1990 intercomparison (Rozanski et al. 1992) also revealed overdispersion of results, which may be linked to difficulties involved in calibration to modern standards. 
TABLE 2. Index of Homogeneity for All Stage 3 Samples

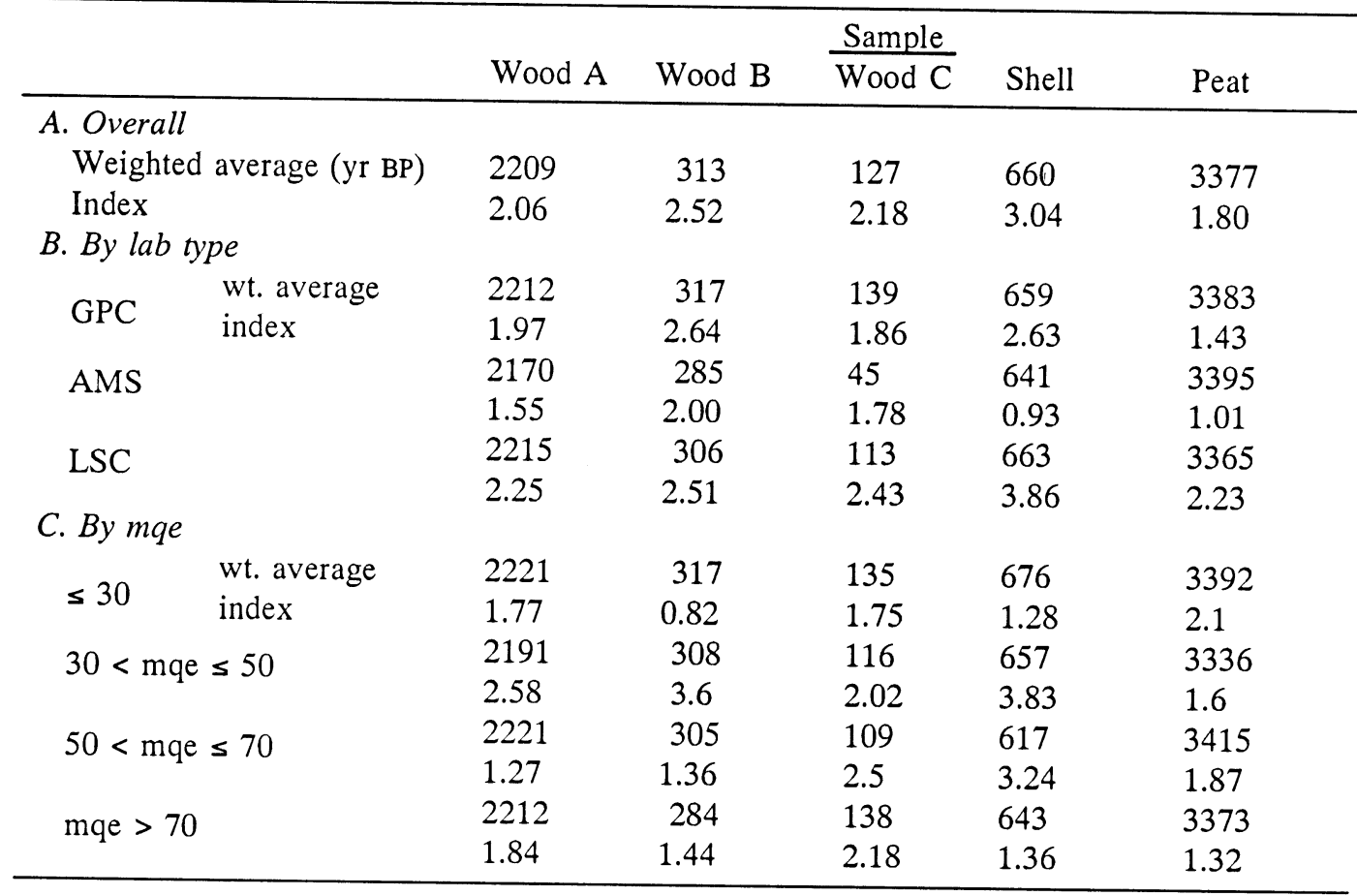

\section{The Analysis of Known-Age Wood Samples from Stages 2 and 3}

Table 3 summarizes the known-age wood samples and their corresponding tree-ring dates, as well as the consensus ${ }^{14} \mathrm{C}$ ages used in the evaluation of the results. Table 4 shows an extract from the calibrations of Pearson and Stuiver (1986), with the appropriate high-precision ${ }^{14} \mathrm{C}$ dates corresponding to tree-ring-dated samples in the same time span as those available in ICS. If we first consider Samples B and C, we see that the consensus ${ }^{14} \mathrm{C}$ values are close to the high-precision values, and that the 'true' difference of 200 years agrees well with the observed average difference of 184 years. Figure 2A shows a histogram of the differences, with a clear mode at 200 years. Figure $2 \mathrm{~B}$ shows a scatterplot of the results, the theoretical line, Wood $\mathrm{C}=200+$ Wood $\mathrm{B}$, indicating that the fit is good. This analysis, as did the duplicate analysis, demonstrates the ability of laboratories to achieve internally consistent results. If we now consider the duplicate samples

TABLE 3. Known-Age Wood Samples

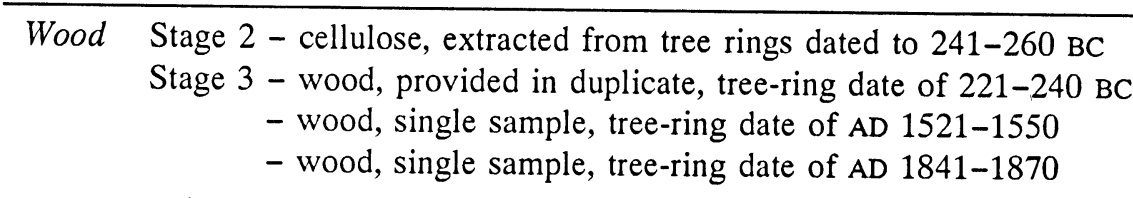

Consensus ${ }^{14} \mathrm{C}$ age values (yr BP)

\begin{tabular}{llll}
$\frac{\text { Stage 2 }}{\text { Cellulose }}$ & Wood A & $\underline{\text { Stage 3 }}$ & \\
2250 & 2218 & 300 & Wood B \\
\hline
\end{tabular}

*Wood B and C were not provided in duplicate. 
TABLE 4A. High-Precision Calibrated Results for Known-Age Samples

\begin{tabular}{|c|c|c|c|c|}
\hline \multirow[t]{2}{*}{ Sample } & \multirow[t]{2}{*}{ Tree-ring age } & \multicolumn{3}{|c|}{$\begin{array}{l}\text { Corresponding }{ }^{14} \mathrm{C} \text { ages } \\
\text { (Pearson \& Stuiver 1986) }\end{array}$} \\
\hline & & Mid- & ${ }^{14} \mathrm{C}$ age & Average \\
\hline \multirow[b]{2}{*}{ Cellulose } & $241-260 \mathrm{BC}$ & $250 \mathrm{BC}$ & $2195 \pm 16$ & \multirow{2}{*}{2223} \\
\hline & mid- $250 \mathrm{BC}$ & $270 \mathrm{BC}$ & $2251 \pm 16$ & \\
\hline \multirow[b]{2}{*}{ Sample A } & $221-240$ вC & $210 \mathrm{BC}$ & $2206 \pm 13$ & \multirow{2}{*}{2195} \\
\hline & mid- $230 \mathrm{BC}$ & $230 \mathrm{BC}$ & $2183 \pm 17$ & \\
\hline \multirow{2}{*}{ Sample B } & AD $1521-1550$ & $\mathrm{AD} 1535$ & $314 \pm 16$ & \multirow{4}{*}{293} \\
\hline & $\mathrm{AD}$ mid- 1535 & AD 1525 & $273 \pm 14$ & \\
\hline \multirow{2}{*}{ Sample C } & $\mathrm{AD} 1841-1870$ & AD 1840 & $95 \pm 10$ & \\
\hline & AD mid-1855 & & & \\
\hline
\end{tabular}

TABLE 4B. Calibrated Results

\begin{tabular}{lccc}
\hline & Cellulose & Wood A & Wood B \\
\hline${ }^{14} \mathrm{C}$ age & 2250 & 2218 & 300 \\
Assumed $\sigma$ & 10 & 10 & 10 \\
$95 \%$ interval & $386-365 \mathrm{cal} \mathrm{BC}$ & $369-352 \mathrm{cal} \mathrm{BC}$ & cal AD 1523-1565 \\
& $279-262 \mathrm{cal} \mathrm{BC}$ & $311-271 \mathrm{cal} \mathrm{BC}$ & cal AD 1634-1642 \\
& & $269-238 \mathrm{cal} \mathrm{BC}$ & \\
& & $230-210 \mathrm{cal} \mathrm{BC}$ & \\
\hline
\end{tabular}

Note: Wood C could not be calibrated.

of cellulose and whole wood, the corresponding high-precision ${ }^{14} \mathrm{C}$ ages are 2223 and $2195 \mathrm{BP}$. The consensus values agree well, supporting the previous use of these consensus values in estimating bias. Further, the ${ }^{14} \mathrm{C}$ results for Sample $\mathrm{A}$ are in broad agreement with the ${ }^{14} \mathrm{C}$ values corresponding to tree-ring age $221-240 \mathrm{BC}$ in the high-precision calibration work of Pearson and Stuiver (1986).

Table 4B shows the results of calibrating the consensus ${ }^{14} \mathrm{C}$ values using the probabilistic approach (van der Plicht \& Mook 1989). The calibrated results for Wood A and B overlap the known tree-ring date, although for Sample A, they cover a broad range, and include multiple solutions. The calibrated results for the cellulose do not, in fact, include the tree-ring dates.

\section{${ }^{13} \mathrm{C}$ and Its Influence}

The final factor considered here is the $\delta^{13} \mathrm{C}$ values quoted for each sample. Again, we concentrate on Stage 3, before looking at the related samples in Stage 2. We investigate the level of variability in $\delta^{13} \mathrm{C}$, and how it relates to the overall variability in the ${ }^{14} \mathrm{C}$ results.

Table 5 summarizes the $\delta^{13} \mathrm{C}$ values for each sample and the correlations between ${ }^{14} \mathrm{C}$ age and $\delta^{13} \mathrm{C}$. We find no evidence of a significant linear relationship between the two, thus, $\delta^{13} \mathrm{C}$ provides little clue to the source of overdispersion in the results.

If we now compare the $\delta^{13} \mathrm{C}$ values of the cellulose and humic acid in Stage 2, with those for whole wood $\mathrm{A}$ and peat in Stage 3, we find a small significant difference, (the whole wood $\delta^{13} \mathrm{C}$ is lighter than that for cellulose, and the humic acid $\delta^{13} \mathrm{C}$ is lighter than that for the whole peat). 


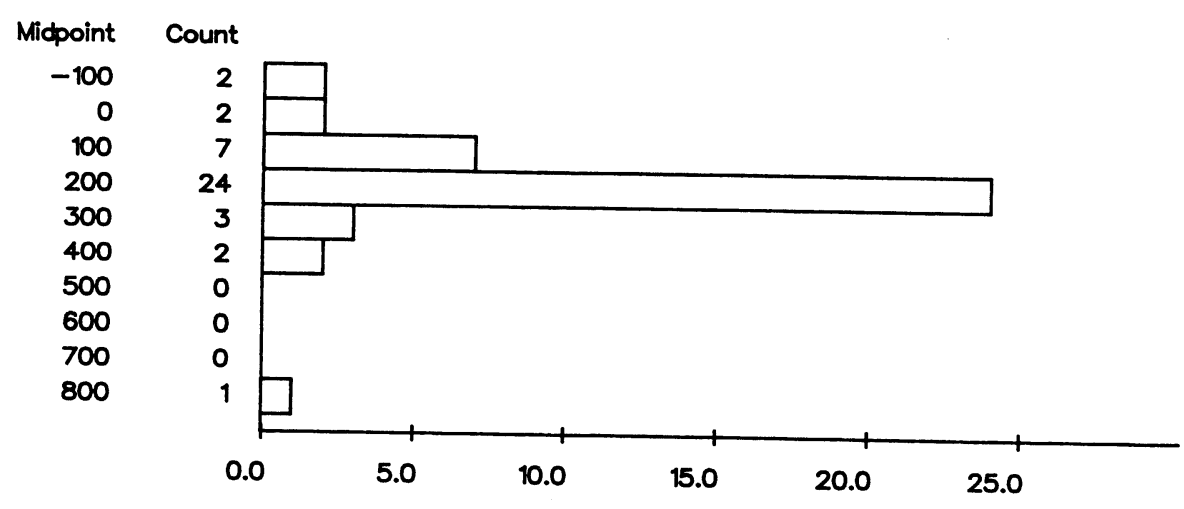

Fig. 2A. Histogram of the differences between wood samples B and C

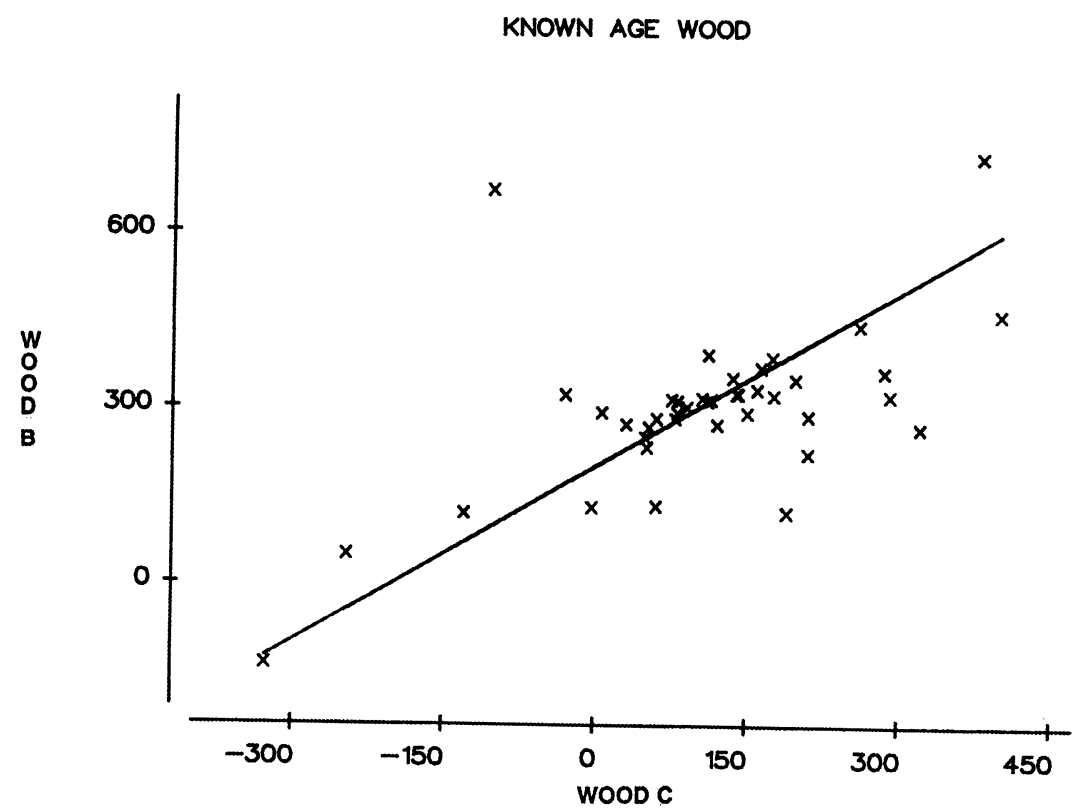

Fig. 2B. Scatterplot of results for wood samples B and C showing theoretical ${ }^{14} \mathrm{C}$ relation

TABLE 5. $\delta^{13} \mathrm{C}$ Summaries

\begin{tabular}{lll|lllll}
\hline & Stage 2 & \multicolumn{5}{c}{ Stage 3 } \\
Sample & Cellulose & $\begin{array}{l}\text { Humic } \\
\text { acid }\end{array}$ & Wood A & Wood B & Wood C & Shell & Peat \\
\hline $\begin{array}{l}\text { Mean }{ }^{13} \mathrm{C} \\
\text { value }\end{array}$ & -24.1 & -28.60 & -25.15 & -25.10 & -25.90 & 1.30 & -28.30 \\
$\begin{array}{l}\text { Correlation } \\
\text { with }{ }^{14} \mathrm{C} \text { age }\end{array}$ & -0.102 & 0.165 & 0.212 & 0.122 & 0.255 & 0.254 & 0.098 \\
\hline
\end{tabular}




\section{CONCLUSIONS}

We have further investigated the data base of results from the ICS and in particular, the variability in the results for each sample. We find evidence of overdispersion of results, which is not purely sample-derived, and that the level of inhomogeneity apparent in the results is not dependent solely on laboratory type.

Analysis of the known-age material confirms the use of the previously defined consensus values, and demonstrates that, in the context of intercomparison, provided that a sufficient number of results are available, a consensus value defines an appropriate baseline.

The $\delta^{13} \mathrm{C}$ values show a non-significant correlation with the ${ }^{14} \mathrm{C}$ ages. This finding might be expected, given the low level of variation among the $\delta^{13} \mathrm{C}$ values themselves.

\section{ACKNOWLEDGMENTS}

The authors gratefully acknowledge the financial support of the Science and Engineering Research Council, and in particular, the contribution of all participant laboratories.

\section{REFERENCES}

Cook, G. T., Harkness, D. D., Miller, B. F., Scott, E. M., Baxter, M. S. and Aitchison, T. C. 1990 International Collaborative Study: Structuring and sample preparation. In Scott, E. M., Long, A. and Kra, R. S., eds., Proceedings of the International Workshop on Intercomparison of Radiocarbon Laboratories. Radiocarbon 32(3): 267-271.

Long, A. and Kalin, R. M. 1990 A suggested quality assurance protocol for radiocarbon dating laboratories. In Scott, E. M., Long, A. and Kra, R. S., eds., Proceedings of the International Workshop on Intercomparison of Radiocarbon Laboratories. Radiocarbon 32(3): 329-335.

Pearson, G. W. and Stuiver, M. 1986 High precision calibration of the radiocarbon time scale 500-2500 BC. In Stuiver, M. and Kra, R. S., eds., Proceedings of the 12 th International ${ }^{14} \mathrm{C}$ Conference. Radiocarbon 28(2B): 839-862.

Rozanski, K., Stichler, W., Gonfiantini, R., Scott, E. M., Beukens, R. P., Kromer B. and van der Plicht, J. 1992 The IAEA ${ }^{14} \mathrm{C}$ Intercomparison Exercise 1990. Radiocarbon, this issue.
Scott, E. M., Aitchison, T. C., Harkness, D. D., Cook, G. T. and Baxter M. S. 1990 An overview of all three stages of the International Radiocarbon Intercomparison. In Scott, E. M., Long, A. and Kra, R. S., eds., Proceedings of the International Workshop on Intercomparison of Radiocarbon Laboratories. Radiocarbon 32(3): 309-321.

Scott, E. M., Long, A. and Kra, R. S., eds., 1990 Proceedings of the International Workshop on Intercomparison of Radiocarbon Laboratories. Radiocarbon 32(3): 253-397.

van der Plicht, J. and Mook, W. G. 1989 Calibration of radiocarbon ages by computer. In Long, A. and $\mathrm{Kra}$, R. S., eds., Proceedings of the 13 th International ${ }^{14} \mathrm{C}$ Conference. Radiocarbon 31(3): 805-816.

Ward, G. K. and Wilson, S. R. 1978 Procedures for comparing and combining radiocarbon age determinations: A critique. Archaeometry 20(1): 19-31.

Wilson, S. R. and Ward, G. K. 1981 Evaluation and clustering of radiocarbon age determinations: Procedures and paradigms. Archaeometry 23(1): 19-39. 
APPENDIX 1.

(I) Internal Error Multiplier (IEM)

Notation: $\quad X_{1 j}$ and $X_{2 j}$ are duplicate results on the $\mathrm{j}^{\text {th }}$ sample for an individual laboratory with corresponding quoted errors, $S_{1 j}$ and $S_{2 j}$.

We assume $\mathrm{X}_{1 \mathrm{j}} \sim \mathrm{N}\left(\mu_{\mathrm{j}}, \theta \mathrm{S}_{1 \mathrm{j} 2}\right)$ where $\mu_{\mathrm{j}}$ is the 'true age'

$\mathrm{X}_{2 \mathrm{j}} \sim \mathrm{N}\left(\mu_{\mathrm{j}}, \theta \mathrm{S}_{2 \mathrm{j}}\right) \sqrt{\theta}$ is the IEM

i.e., $\mathrm{X}_{1 \mathrm{j}}$ and $\mathrm{X}_{2 \mathrm{j}}$ are Normally distributed

let $\quad \mathrm{d}_{\mathrm{j}}=\mathrm{X}_{1 \mathrm{j}}-\mathrm{X}_{2 \mathrm{j}}$

then $\quad d_{j} \sim N\left(0, \theta S_{j 2}\right) S_{j 2}=S_{1 j}+S_{2 j}$.

Likelihood $=\quad \frac{1}{(2 \pi) \frac{\pi}{2}} \theta^{-\frac{n}{2}} \prod_{j} S_{j-1} \exp \left[-\frac{1}{2} \sum \frac{d_{j 2}}{\theta S_{j 2}}\right]$

$\log$ likelihood $=\frac{n}{2} \log \theta-\sum_{j} \log S_{j}-\frac{1}{2} \sum \frac{d_{j} 2}{\theta S_{j} 2}$.

The value of $\theta$, which maximizes the likelihood function is given by

$$
\begin{aligned}
& \frac{\delta}{\delta \theta}=\frac{n}{2 \theta}+\frac{1}{2} \sum \frac{d_{j^{2}}}{s_{j^{2}}} \cdot \frac{1}{\theta^{2}}=0, \\
& \text { i.e., } \quad \frac{1}{\theta}\left[-\frac{n}{2}+\frac{1}{2 \theta} \sum \frac{d_{j^{2}}}{S_{j^{2}}}\right]=0, \\
& \text { i.e., } \quad \frac{1}{\theta} \sum_{j} \frac{d_{j^{2}}}{s_{j^{2}}}=n, \\
& \text { hence, IEM }=\sqrt{\frac{\sum \frac{d^{2}}{s_{j^{2}}}}{n}} .
\end{aligned}
$$

(II) Index of Homogeneity $\sigma_{\mathrm{W}}$ (Ward \& Wilson, 1981)

$$
\begin{aligned}
& \text { Data: } X_{1}, \ldots, X_{n} \\
& s_{1}, \ldots, s_{n} \\
& \mathrm{x}_{\mathrm{i}},{ }^{14} \mathrm{C} \text { date, and } \mathrm{s}_{\mathrm{i}} 1 \sigma \text { error } \\
& \text { then } \quad \bar{x}_{W}=\frac{\sum_{i} \frac{x_{i}}{s_{i}^{2}}}{\sum \frac{1.0}{s_{i}^{2}}} \\
& \text { hence } \quad \hat{\sigma}_{W}=\sqrt{\frac{1}{n} \frac{\sum\left(x_{i}-\bar{x}_{W}\right)^{2}}{s_{i}{ }^{2}}} \text {. }
\end{aligned}
$$

